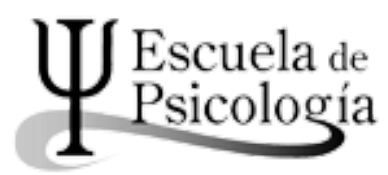

Wímb lu, Rev. electrónica de estudiantes Esc. de psicología, Univ. de Costa Rica. 11 (1): 7-17, 2016 / ISSN: 1659-2107

\title{
De lo moral en el arte y en la crítica: consideraciones sobre la era de la reproducción técnica y los críticos de la "cultura de masas"
}

\author{
About moral in art and critics: considerations about \\ technical reproduction era and critics of "mass culture"
}

Bruno Carignano*

\begin{abstract}
Resumen: El artículo examina las consecuencias que tiene la reproducción técnica sobre la estética partiendo de algunos análisis de Benjamin en "La obra de arte en la época de su reproductividad técnica". Se toma lo moral como categoría implícita que opera en este autor, ligada a los argumentos que permiten indagar diversas modalidades de tramitación de lo ético en lo estético. En este sentido, se interrogan sus análisis del futurismo y el dadaísmo, precisando la lectura sintomal de estos movimientos artísticos como expresiones diversas que permiten considerar aspectos de la colisión novedosa entre moral y estética que la era de la reproducción técnica propició. Este particular abordaje benjaminiano de lo moral es contrastado con las réplicas a la cultura de masas que despliegan Adorno y Horkheimer, figuras de la crítica fuertemente condicionadas por dicho advenimiento. El impacto de lo moral, embanderado en el concepto fetiche de "industria cultural" (Eco), golpea allí con otra fuerza, insertándose en un encadenamiento argumental muy distante al de Benjamin. El artículo concluye enfocando dos metamorfosis conceptuales concretas (de la "dispersión" a la "distracción", y de la "reproducción técnica" a la "imitación"), ilustrativas de la distancia de los análisis en ambos casos.
\end{abstract}

Palabras clave: Estética, moral, crítica, reproducción técnica, cultura de masas.

Universidad Nacional de Rosario (UNR) y UCES, Docente psicoanalista. Argentina.

Correo electrónico: brunocarignano@yahoo.com

Recepción: 25/6/2015 Aceptación: 20/7/2015 
Abstract: The paper examines the consequences of mechanical reproduction on aesthetic, taking into account certain analysis by Benjamin in "The Work of Art in the Age of works. This fact is linked to some arguments that lead to the questioning of the relation between ethic and aesthetic. In this sense Benjamin's own analysis of futurism and dadaism are questioned with the aim of making precise the symptomatic interpretation of this movements, as different expressions of the original collision between morality and aesthetic, that the age of mechanical reproduction have promoted. This particular approach of morality is compared to the response against "mass culture", such as posed by Adorno and Horkheimer, art critics strongly conditioned by it. The impact of morality, related to the fetishistic concept of "industrial culture" (Eco), has a different strength in this specific case. There, the relations of arguments is quite distant from the ones that exist in Benjamin's considerations. The conclusion focuses on two specific conceptual metamorphosis (from "dispersion" to "distraction", from "mechanical reproduction" to "imitation") that illustrate the distance between the analysis in both cases.

Key Words: Aesthetic, morality, critics, mechanical reproduction, mass culture.

\section{Introducción}

Aunque no se puedan extraer conclusiones morales de las posiciones estéticas, es indudable que en toda adopción de una estética hay una cierta moral sugerida

O. Masotta

So steht es um die Ästhetisierung der Politik, welche der Faschismus vertreibt. Der Kommunismus antwortet ihm mit der Politisierung der Kunst

W. Benjamin

Una de las tesis centrales de Walter Benjamin sostiene que la reproducción técnica produce un impacto tal que modifica todo el arte en su conjunto. Aunque no sea una cuestión abordada como tal y en estos términos por el autor, es importante, a los fines que me propongo, situar de entrada el problema de la técnica en relación con un sintagma vuelto posteriormente célebre, el de "cultura de masas"; noción, según Umberto Eco, fetichizada por la crítica.

Si "la obra de arte ha sido siempre susceptible de reproducción" (Benjamin, 2007, p.148), el carácter auténtico de la obra original, puesto en cuestión por la reproducción a secas (la llamada por Benjamin "reproducción manual") aunque no sin otorgarle por ello, paradójicamente, más autoridad al original (puesto que se distingue de él como falsa copia de la auténtica), es terminantemente arrasado por la reproducción técnica. ¿Es una tesis de índole moral lo que se nos propone? ¿Se trata en definitiva de un juicio sobre un mejor o peor estado del arte en función de los avances técnicos?

\section{Argumentos de Benjamin frente a cierta ceguera moral de la crítica}

Aún cuando los argumentos parezcan por momentos inclinados en dicha direccion, es evidente que Benjamin se sitúa más allá, escapando a lo que podría operar como una ceguera moral en la dilucidación crítica, ceguera que $s$ encontramos como contrapunto en otros autores. Sólo leídas sus afirmaciones desde cierto registro superficial, incluirían implícitamente una concepción del arte ligada a la degradación que sufriría en el período de su reproducción técnica. Por ejemplo, reflexionando sobre el carácter de lo auténtico como lo que define a la obra de arte original, cierto lector apresurado podría mecánicamente deducir su opuesto en la inautenticidad que se le impondría a la obra técnicamente reproducida. Sin embargo, la cuestión es más compleja de lo que parece en una primera percepción, porque el examen de ese nuevo estado del arte en que no bastan las nociones de autenticidad y aura, consustanciales al arte clásico (prereproducción técnica), lejos de llevar a un pensamiento que concluye por el déficit (distinguiendo lo inauténtico de lo auténtico), conduce más bien a considerar a arte en función de una nueva praxis que corre el eje clásico del ritual: la política. Si el modo de circunscribir que "falta algo" (aura, autenticidad) en la reproducción técnica parece requerir cierto tinte de juicio moral que encontraremos elevado a la máxima potencia, como pliegue inherente de la sanción estética, en los fundamentos morales-emotivos pesquisados por Eco como condición de la obnubilación de los críticos por él calificados de apocalípticos - que rechazan todo "en bloque" (1968), todo lo considerado "cultura de masas", sin tomarse siquiera el trabajo de analizar las producciones que la componen y establecer diferencias -, es, en un segundo movimiento no menos esencial a la argumentación benjaminiana, neutralizado al máximo: precisamente cuando una torsión fundamental transforma, lo que podría haber sido leído como prejuicio moral, en categoría que nutre el análisis de las determinaciones históricas de la estética. Donde se entiende que 10 moral (que tomamos como categoría implícita que opera en Benjamin, no como prejuicio personal, sino como argumento ligado a la modalidad de tramitación histórica de lo ético en lo estético) pasa a estar asociado a la praxis de la política, tal como es explicitado por Benjamin. En dicho punto, el lector debería perder ya siquiera toda sospecha de que lo moral pudiera estar oficiando como sostén y fundamento en este autor de una ceguera crítica ante el nuevo modo de manifestación del arte; aún cuando pueda afirmar estrepitosamente que ese arte "ha escapado del reino de la apariencia de lo bello" (Benjamin, 2007, p.165). De allí no se deduce un arte menos arte por alejarse del clasicismo de lo bello, sino un hondo cuestionamiento sobre los efectos estéticos de los nuevos modos del arte a partir de la reproducción técnica, para los que la categoría de la recepción como contemplación queda demasiado estrecha ${ }^{1}$. Dicha afirmación no está apoyada en una dicotomía 
paralizante del tipo buen arte en contra de arte degradado, tal como se la encuentra, por momentos, operando en las réplicas a la cultura de masas con que avanzan Theodor Adorno y Max Horkheimer, autores de "La industria cultural. Iluminismo como mistificación de masas".

Como razón probatoria de ello debe atenderse al modo en que Benjamin rescata de Duhamel argumentos pertinentes referidos a la dilucidación de las particularidades estéticas del cine (enfocando especialmente los efectos sobre el receptor) sin quedar prendido del juicio moral que lo rechaza. Sostiene Duhamel: "Ya no puedo pensar lo que quiero. Las imágenes movedizas sustituyen a mis pensamientos" (Benjamin, 2007, p.177). En el caso de este autor, observamos como lo moral, expresado en la forma de un rechazo enérgico del cine como nueva forma del arte, aparece vinculado a esa manera de juzgar en la que el crítico se encuentra demasiado implicado en su disgusto, aunque no por ello obnubilado al punto de ser incapaz de transmitir una verdad sobre la estética que juzga (de una forma no lejana tal vez a lo que ocurre en las sentencias de algunos críticos apocalípticos examinadas por Eco, aunque lo moral pueda también, en ocasiones, taponar la emergencia de una verdad sobre el objeto examinado). Es precisamente esa verdad estética la que Benjamin rescata de Duhamel, reteniendo lo perspicaz del argumento, pero haciendo a un lado el tono negativo o disgusto personal de este crítico. Así es que puede sostener, en referencia a este autor, que "odia el cine y no ha entendido nada de su importancia, pero sí lo bastante de su estructura" (Benjamin, 2007, p.177). Veamos lo que que está fundamentalmente en juego en esa lectura: la validación de esa afirmación en que la relación entre imágenes cinematográficas y pensamiento dirige a esa novedosa forma de estética en que la obra cobra valor de proyectil sobre el receptor. Se trata de rescatar las profundas modificaciones en el aparato perceptivo que el cine produce, equiparadas a "las que hoy vive a escala de existencia privada todo transeúnte en el tráfico de una gran urbe" (Benjamin, 2007, p.177). El contraste entre el posicionamiento crítico de los dos autores se acentúa en la prosecución del argumento de Benjamin, cuando se evidencia como la intervención moral en el juicio estético puede culminar por coagular los enunciados en una esfera superficial. Según Duhamel, el cine es:

pasatiempos para parias, disipación para iletrados, para criaturas miserables aturdidas por sus trajines y preocupaciones..., un espectáculo que no reclama esfuerzo alguno, que no supone continuidad en las ideas, que no plantea ninguna pasión, que no alumbra ninguna luz en el fondo de los corazones, que no excita nasón, que no alumbra con en Los Angeles (Benjamin, 2007, p.178).

En este punto, al arribarse a la cuestión del examen de la relación entre la creciente participación de las masas que el cine propugna y el modo en que efectivamente ellas participan de su recepción, la verdad alcanzada por Duhamel queda ya desacreditada. Distanciándose, así concluye Benjamin:

El crecimiento masivo del número de participantes ha modificado la índole de su participación. Que el observador no se llame a engaño porque dicha participación aparezca por de pronto bajo una forma desacreditada. No han faltado los que guiados por su pasión, se han ater
(2007, p.178, destacado mío).

No interesa entrar aquí en el detalle del asunto, esto es, en el contenido conceptual en disputa, sino apuntar cómo, con una torsión argumental, Benjamin pone en el tapete la polémica en el plano que le interesa, como si transcribiera los prejuicios morales en otro registro, dándole un alcance más universal: "en el fondo se trata de la antigua queja: las masas buscan disipación, pero el arte reclama recogimiento" (2007, p.178). Ello le permitirá avanzar desde otro ángulo, trayendo a sus argumentos la obra de arte por excelencia "cuya recepción sucede en la disipación" (Benjamin, 2007, p.179), la arquitectura. El camino había sido señalado por la pasión enceguecedora de Duhamel, contrariado por un estética que rompía el lazo entre recepción y recogimiento que proclamaba como indisoluble para el arte (lo que lee Benjamin como operando implícitamente). Uno de sus méritos circunstanciales es haber mostrado, con la fuerza del ejemplo histórico de la arquitectura, que ese lazo no era tan estrecho ni siquiera en el mismo arte clásico. El enfoque del fenómeno desde otro ángulo de las artes le permite ahondar la relación entre recepción y disipación en el cine como nuevo hecho estético que viene a retranscribir la especificidad de una percepción en la disipación, con el consiguiente efecto de domesticarla, lo que sintetiza la expresión de "inconsciente óptico"2 como calificativa de las posibilidades de la cámara cinematográfica en la percepción visual y táctil: "Con el primer plano se ensancha el espacio y bajo el retardado se alarga el movimiento"; "La naturaleza que habla a la cámara no es la misma que la que habla al ojo" (Benjamin, 2007, p.174).

\section{Lo moral como categoría para interrogar manifestaciones estéticas: los casos del futurismo y el dadaísmo}

De acuerdo a lo que he venido señalando, interesa especialmente destacar el hecho de que lo moral oficia como una suerte de categoría de análisis para Benjamin, lo que da un vigor y alcance especial a su argumentación. Interpretamos que la política y lo cultual, como modos de registros de los impactos sociales de las producciones artísticas que sirven para trazar el contrapunto entre el arte en su forma tradicional y el arte en la época de su reproducción técnica, son introducidos como categorías no ajenas a lo moral, lo que se acentúa especialmente a partir 
de las conclusiones que pueden extraerse de ellas. Los movimientos artísticos posteriores a las revoluciones técnicas del cine y la fotografía poseen el valor de síntomas que expresan la relación entre política y arte, como modos sociales de tramitación de la nueva colisión entre moral y estética que la era de la reproducción técnica manifestó. Es así que el futurismo podrá ser interpretado como el emergente fundamental de que "la sociedad no estaba todavía lo bastante madura para hacer de la técnica su órgano" (Benjamin, 2007, p.182), movimiento que encuentra en la expresión "la guerra es bella", proclama artística del manifiesto de Marinetti, una síntesis acabada de una de las posibles formas de amalgama entre estética y moral en la época de la reproducción técnica. Si seguimos la consideración de Oscar Masotta (expresada en el epígrafe), es evidente que puede deducirse una moral de la estética futurista de la guerra; pero habría que decir que sólo a partir del manifiesto que la acompaña puede hablarse, en este caso, de una conclusión moral de determinada posición estética, levantando la justa y precisa restricción de este autor.

En el dadaísmo encontramos otro de los ejemplos de la lectura sintomal de los movimientos artísticos a raíz de la tensión que técnica y moral producen en arte. El dadaísmo propulsaba, sin los medios técnicos del cine, ir más allá de la contemplación concebida como el modo clásico de recepción de la pintura; intentaba producir sobre el receptor el efecto de choque del proyectil, en el desplazamiento de lo óptico a lo táctil, que el cine por sus medios técnicos producirá ya sin mayor dificultad. La facilidad técnica dispensa al cine de la potencia moral con que el dadaísmo se oponía a la pintura tradicional. Esa particular forma de moralización de la estética es la expresión sintomática de un arte ya transformado por el advenimiento de la técnica, aunque sin servirse de sus recursos: "Por virtud de su estructura técnica el cine ha liberado al efecto físico de choque del embalaje por así decirlo moral en que lo retuvo el dadaísmo" (Benjamin, 2007, p.177).

\section{Antropología de la cultura de masas: "La industria cultural" y el crítico como víctima. Esbozo de conclusión a partir de dos deslizamientos conceptuales}

Vimos, tal como Benjamin lo señala, cómo las modificaciones del aparato perceptivo que la revolución técnica del cine promueve son correlativas de las que alcanzan al transeúnte de la gran urbe en su vida privada. De esta forma, poniendo el acento en la recepción estética, el autor muestra lo irremediable del impacto de la técnica en la vida privada y cotidiana de cada uno: de lo que puede inferirse que el acento en los medios por los que se afirma la cultura de masas no coloca el eje en una eventualidad que podría erradicarse, sino que lo dirige más bien hacia una forma propiamente moderna de recibir mensajes estéticos. Con ello, marginalmente, Benjamin apunta un dato que Eco hará estandarte de su posición, enfatizando su concepción antropológica de la "cultura de masas", único registro en que este sintagma pierde su halo fetichista por hincarse en el problema de la "comunicación de masas", marco insoslayable de la cuestión (Eco, 1968). La comunicación de masas es un dato de hecho del que no podemos escapar, ni aún el crítico más acérrimo de la cultura de masas consigue desprenderse de sus condicionamientos, ese crítico obsesionado con la disensión, bautizado por Eco como "apocalíptico". Si este autor se aboca a las distinciones internas a la "cultura de masas", al estudio de la pluralidad de manifestaciones heterogéneas que ingresan ocultas y amalgamadas en ese sintagma, es para mostrar que no hay homogeneidad imperante en sus producciones. La expresión "cultura de masas" es como tal inutilizable, por esconder la gran diferencia de productos dentro del único hecho irrevocable: la comunicación de masas, que condicionará insoslayablemente tanto el arte como la crítica, pero no por ello de manera uniforme. El "hombre-masa" es un cliché fetichista a menos que pueda mostrarse, como lo sugiere Eco, que cierta modalidad de transmisión y atascamiento de los mensajes constituye cierto modelo de destinatario, al que sí podría ya legítimamente calificarse de hombre-masa. En dicho caso, esta noción no cubrirá la totalidad de las nuevas producciones artísticas, sino sólo una zona circunscripta en la cual un análisis estructural habría de distinguir una limitada especificidad de mensajes estéticos.

Tal como propone Eco, "surge la sospecha de que la primera y más ilustre víctima del producto de masas sea el propia crítico" (1968, p.37). Analizando algunos modos de razonamientos de Adorno y Horkheimer como figuras de la crítica que han sido condicionadas por el advenimiento de la llamada cultura de masas, intentaremos apuntar el modo de la inserción que allí tiene lo moral, en su palmaria diferencia con el tratamiento que hace Benjamin. En "La industria cultural" encontramos un fundamento emotivo ${ }^{3}$ que en ocasiones pareciera operar como una obturación moral del discernimiento crítico de lo estético y, como consecuencia de ello, distinciones simplistas que recaen en la disyunción entre un buen arte clásico y un mal arte contemporáneo. Es notorio cómo, en dicho ensayo, no se procede a la distinción del material examinado: todo producto de la cultura de masas es tratado como una totalidad indiferenciada. Aunque los ejemplos abunden y sea exhaustivos, no se los examina en su posible diferencia estructural interna para esbozar siquiera mínimas distinciones. Y aún cuando se filtre de forma diseminada en algunas frases la disimulada sospecha de que todo producto de la cultura de masas no puede ser equivalente a los demás ${ }^{4}$, no se transforma esa insinuación, tal vez no querida, en herramienta de análisis que establezca diferenciaciones. 
En "La industria cultural" el impacto de lo moral golpea con otra fuerza y se inserta en una lógica argumental muy distante a la de Benjamin. Podemos tener inicialmente una idea de dicho impacto si retenemos la expresión "barbarie estilizada" con que estos autores se refieren a la industria cultural (Adorno y Horkheimer, 1988). Sería inevitable no vernos reenviados, a partir de esta noción, al estancamiento superficial de Duhamel que más arriba comentamos. El sintagma "barbarie estilizada" nos deja ver cómo se rechaza todo "en bloque", sin que sean analizadas las diferencias formales y de contenido entre las diversas producciones artísticas. Todo pareciera entrar dentro de la barbarie para estos autores: los dibujos animados, la radio, el cine, la música "noble" puesta a circular en la comunicación de masas, la cancioncilla de consumo, las stars del cine, etc. Secuencia desopilante que nos recuerda a la extravagante serie borgeana de la enciclopedia china que arrancaba la carcajada de Foucault al comienzo de Las palabras y las cosas.

Tomemos por caso esta afirmación: "la radio puede convertirse en la boca universal del Führer" (Adorno y Horkheimer, 1988), para atender a un procedimiento que abunda en el texto y desborda absolutamente este ejemplo particular: el anonadamiento del crítico ante la instauración de un nuevo medio técnico arrasa con las distinciones internas a la transmisión del mensaje estético. En este caso concreto vemos como la radio es vituperada por la llanura de un juicio moral sobre la técnica que disuelve las potenciales diferencias asociadas a la diversidad de mensajes posibles.

Otro ejemplo, que en este caso nos permite medir la distancia entre Ardorno/ Horkheimer y Benjamin, es el movimiento de l'art pour l'art. En Benjamin ocupaba un lugar importante en su razón argumental, pero no implicaba más que un análisis circunspecto del lugar de lo teológico en el arte (como modalidad específica de tramitación estética de lo moral) y de sus modos paradójicos de vinculación con lo político-social. Para Adorno y Horkheimer se transforma en el modo genérico de subsistencia mercantilizada del arte en el mundo capitalista. La bandera anclada en el concepto fetiche de "industria cultural" (Eco, 1968, p.33) transforma a la cultura en una mera mercancía del proceso de producción capitalista. Es cierto que se trata, al decir de los autores, de una "mercancía paradójica"5, pero ello no complejiza el análisis hacia una posible diversificación interna de los productos.

El supuesto nuevo estilo se nos presenta más bien como una "negación del estilo", que procedería, al decir de los autores, a partir de una turbia identidad de lo universal con lo particular, instaurando el marco para situar a la "obra mediocre" de la "no cultura". ¿Es legítimo hablar de un nuevo estilo? ¿Hay un único estilo inherente a la cultura de masas? Ése es precisamente el prejuicio que Eco desmonta al examinar las afirmaciones de Adorno sobre el producto musical en la cultura de masas. Adorno homologa "la innoble cancioncilla de consumo" al producto artístico más noble al ser ingresado al "circuito del consumo de masas" (Eco, 1968, p.101) por entender que "en ambos casos, la relación típica entre hombre masificado y producto artístico comercializado se configura como irreflexiva y no analizable adoración de un objeto fetiche" (Eco, 1968, p.101). De este análisis, puede concluirse que la actitud es totalmente improductiva porque no consigue quebrar la falsa uniformidad entre los fetiches del hombre-masa consumidor y el objeto consumido. Como más arriba lo indicamos, si la categoría de hombre-masa puede conservar un sentido es sólo como producción saturada de un tipo específico de mensajes estéticos dentro del circuito de comunicación de masas y no como condición universalizable de cualquier producto que se introduzca en dicho circuito ${ }^{6}$.

La distancia entre los autores se acentúa aún más cuando se la pesquisa en dos metamorfosis conceptuales concretas: en un caso, la "dispersión" es suplantada por la "distracción" y, en otro, la "reproducción técnica" por la "imitación". La noción de reproducción técnica en que hacía hincapié Benjamin ha sido rebajada a la imitación: "La industria cultural absolutiza, en suma, la imitación" (Adorno y Horkheimer, 1988) como manera de resolución del fracaso por alcanzar la identidad (constitutiva, según los autores, de toda riqueza estilística) en esta manifestación degradada del arte. El imperativo de la reproducción técnica es uniformemente entendido como proceso de producción en serie del sistema social, a raíz de lo cual pueda estar tal vez justificado hablar, también en este caso, de "formulaciones pseudormaxistas de la escuela de Frankfurt" (1968, p.35), dándole una mayor extensión a la aserción de Eco. Por otro lado, lo que para Benjamin era cuestionado como la especificidad de una estética que ocurría en la dispersión (con fundamentos puntuales en la serie: arquitectura-cine-urbe), pasa a ser descalificado como una distracción de la recepción sin que nunca se entienda muy bien en qué se fundamenta. El punto a cuestionar no reside en la descalificación basada en el gusto, que nunca podrá ser dejada de lado en un crítica ligada a la estética, sino en cómo algunos prejuicios fundados en lo que la técnica permite de reproducción y difusión masiva, nublan e impiden un análisis que argumente sobre la materialidad de los productos artísticos.

\section{Notas}

1 Es insoslayable aquí la remisión a lo sublime como categoría indiscutible para pensar los efectos estéticos del arte transformado a partir de la reproducción técnica. Dicho concepto, que se remonta a Burke y que ha sido extensamente trabajado por Kant en la Crítica del juicio, es vanguardia (es sugerente, en ese sentido, mencionar la titulación de uno de los ensayos que componen el libro: "Después de lo sublime, estado de la estética"). Para lo que aquí nos interesa, en cuanto al lugar de lo moral, retenemos especialmente la afirmación de que "lo sublime no es otra cosa que el anuncio sacrificial de la ética en el campo estético" (Lyotard, 1998, p.141, destacado mio). De todas maneras, ello no debería llevar a establecer una repartición tajante del tipo: arte de lo bello (clásico) vs. arte de lo sublime (vanguardias). 
2 Refiriéndose a la cámara, sostiene: "Por su virtud experimentamos el inconsciente óptico igual que por medio del psicoanálisis nos enteramos del inconsciente pulsional" (Benjamin, 2007). los efectos del cine en la recepción estética, en Carlos Kuri (2007). Estética de lo pulsional: Lazo y exclusión entre psicoanálisis y arte. Santa Fe: Ediciones UNL.

3 A ese impacto moral cargado de fuerte tinte sentimental bien podríamos aplicarle ese

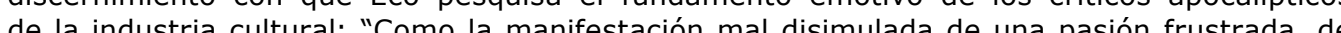
un amor traicionado; más án, como la exhibición neurótica de una sensualidad reprimida semejante a la del moralista que, denunciando la obscenidad de una imagen, se detiene as larga $y$ voluptuosamente en el inmundo objeto de su desprecio, traicionando con este gesto su auténtica naturaleza de animal carnal y concupiscente" $(1968$, p.37/8)

4 Por ejemplo, en afirmaciones del tipo: "la entera cultura de masas, desde el woman serial más idiota hasta la obra cumbre" (Adorno y Horkheimer, 1988)

5 La paradoja reside en que su condición de intercambiable desemboca en la disolución tanto de su valor de cambio como de su valor de uso, conduciendo a la publicidad (respecto de la cual los autores no dejan de explicitar el nombre de Goebbels, de inevitable impacto político y moral) como modo de lectura de l'art pour l'art; se trata, del arte reducido a mera publicidad (el fetiche es la valoración social que anula todo valor de cambio, y que a su vez, se anula a si misma por ser un único valor de uso que elimina cualquier otro valor de uso)

6 Los caminos sin salida de dichos presupuesto se tornan evidentes cuando Eco muestra como un mensaje estético puede ser recibido "según un código que no es aquél de quien lo comunica" $(1968$, p.43), con lo que las categorias de "mensaje masificante" y de "hombre masa" quedan desacreditadas para juzgar una supuesta transmisión uniforme de los mensajes en la cultura de masas.ime

\section{Referencias bibliográficas}

Adorno, Theodor; Horkheimer, Max (1988): "La industria cultural. Iluminismo como mistificación de masas". En Dialéctica del Iluminismo. Buenos Aires: Sudamericana.

Benjamin, Walter (2007). "La obra de arte en la época de su reproductividad técnica". En Conceptos de filosofía de la historia. Buenos Aires: Caronte.

Eco, Umberto (1968). Apocalípticos e integrados. Barcelona: Lumen.

Kuri, Carlos (2007). Estética de lo pulsional. Lazo y exclusión entre psicoanálisis y arte. Santa Fe: Ediciones UNL.

Lyotard, Jean-François (1998). Lo inhumano. Charlas sobre el tiempo. Buenos Aires: Manantial.

Masotta, Oscar (2004). Revolución en el arte. Pop-art, happenings y arte de los medios en la década del sensenta. Buenos Aires: Edhasa.

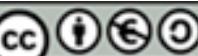

